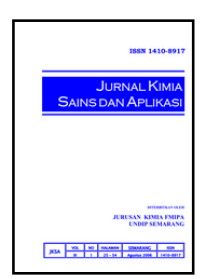

\title{
Pengaruh Temperatur Pengeringan Gel terhadap Konduktivitas Elektrolit Padat $\mathrm{NaMn}_{2-\mathrm{x}} \mathrm{Mg}_{\mathrm{x}} \mathrm{O}_{4}$
}

\author{
Feni Risyanti ${ }^{\mathrm{a}}$, Rahmad Nuryanto ${ }^{\mathrm{a}^{*}}$, Linda Suyati $^{\mathrm{a}}$ \\ a Physical Chemistry Laboratory, Chemistry Department, Faculty of Sciences and Mathematics, Diponegoro University, Jalan Prof. \\ Soedarto, Tembalang, Semarang \\ * Corresponding author: nuryantorahmad@live.undip.ac.id
}

Article Info

Keywords:

solid electrolyte, sol-gel method, conductivity, FTIR, XRD

\section{Abstract}

The preparation of a solid electrolyte $\mathrm{NaMn}_{2-\mathrm{x}} \mathrm{Mg}_{\mathrm{x}} \mathrm{O}_{4}$ with variation of drying temperature has been conducted. The purpose of this study was to determine the effect of gel drying temperature variation on the electrolytic conductivity of $\mathrm{NaMn}_{2-\mathrm{x}} \mathrm{Mg}_{\mathrm{x}} \mathrm{O}_{4}$ solid. The method used in this research was sol-gel method which included stirring, evaporating at $80^{\circ} \mathrm{C}$, drying at temperature variations of $150,160,170,180$ and $190^{\circ} \mathrm{C}$, and calcination at $800^{\circ} \mathrm{C}$. The resulting product was analyzed by conductivity test, FTIR and XRD. The result of conductivity measurement of amorphous solid and solid electrolyte based on variation of drying temperature showed the highest conductivity value obtained at temperature $170^{\circ} \mathrm{C}$ that were respectively $2.27 \times 10^{-9} \mathrm{~S} \mathrm{~cm}^{-1}$ and $22.2 \mathrm{X}$ $10^{-9} \mathrm{~S} \mathrm{~cm}^{-1}$. The lowest conductivity for solid amorphous and electrolyte solids was obtained at a temperature of $150^{\circ} \mathrm{C}$., i.e. $1.87 \times 10^{-9} \mathrm{~S} \mathrm{~cm}^{-1}$ and $12.6 \times 10^{-9} \mathrm{~S} \mathrm{~cm}^{-1}$ respectively.

\section{Abstrak}

Pembuatan elektrolit padat $\mathrm{NaMn}_{2-\mathrm{x}} \mathrm{Mg}_{\mathrm{x}} \mathrm{O}_{4}$ dengan variasi temperatur pengeringan telah dilakukan. Tujuan penelitian ini adalah untuk mengetahui pengaruh variasi temperatur pengeringan gel terhadap konduktivitas elektrolit padat $\mathrm{NaMn}_{2-\mathrm{x}} \mathrm{Mg}_{\mathrm{x}} \mathrm{O}_{4}$. Metode yang digunakan dalam penelitian yang dilakukan adalah metode sol-gel yang meliputi pengadukan, penguapan pada $80^{\circ} \mathrm{C}$, pengeringan pada variasi temperatur $150,160,170$, 180 dan $190^{\circ} \mathrm{C}$, dan kalsinasi pada $800^{\circ} \mathrm{C}$. Produk yang dihasilkan dianalisis dengan uji konduktivitas, FTIR dan XRD. Hasil pengukuran konduktivitas padatan amorf dan elektrolit padat berdasarkan variasi temperatur pengeringan menunjukkan nilai konduktivitas tertinggi diperoleh pada temperatur $170^{\circ} \mathrm{C}$ yaitu masing-masing $2,27 \mathrm{x}$ $10^{-9} \mathrm{~S} \mathrm{~cm}^{-1}$ dan $22,2 \times 10^{-9} \mathrm{~S} \mathrm{~cm}^{-1}$. Konduktivitas terendah untuk padatan amorf dan elektrolit padat diperoleh pada temperatur $150^{\circ} \mathrm{C}$ yaitu masing-masing sebesar $1,87 \mathrm{x}$ $10^{-9} \mathrm{~S} \mathrm{~cm}^{-1}$ dan $12,6 \times 10^{-9} \mathrm{~S} \mathrm{~cm}^{-1}$.

\section{Pendahuluan}

Baterai merupakan sumber energi yang dapat mengkonversi energi kimia menjadi energi listrik yang memiliki beberapa komponen yaitu elektroda, elektrolit dan separator [1]. Penelitian tentang baterai telah banyak dilakukan oleh ilmuwan, salah satunya dengan mengubah elektrolit cair pada baterai menjadi elektrolit padat. Pengubahan elektrolit cair menjadi elektrolit padat dikarenakan elektrolit padat baterai memiliki keunggulan yang tidak dimiliki elektrolit cair baterai yaitu mempunyai waktu simpan yang lama, tidak korosi dan bebas bahaya kebocoran sehingga elektrolit padat dapat mengatasi keterbatasan pada elektrolit cair baterai [2].

Pembuatan elektrolit padat baterai dapat di menggunakan logam litium dengan menyisipkan logam magnesium menggunakan metode sol-gel. Keberadaan logam litium yang tidak melimpah di alam dapat diganti 
dengan logam natrium karena logam natrium merupakan raw materials dengan harga yang lebih murah dibandingkan litium [3] dan kecepatan ion natrium dalam menghantarkan listrik menunjukkan sifat kimia yang mirip dengan ion litium [4].

Penggunaan metode sol-gel dilakukan untuk menghasilkan produk dengan tingkat homogenitas yang tinggi saat proses pencampuran reaktan dan memberikan tingkat kemurnian produk yang tinggi [3]. Proses metode sol-gel meliputi penguapan, pengeringan dan kalsinasi. Hasil dari pengeringan gel yang menunjukkan terbentuknya padatan amorf mendorong penelitian ini dilakukan dengan variasi temperatur pengeringan untuk menunjukkan pengeruh variasi temperatur pengeringan gel terhadap konduktivitas elektrolit padat $\mathrm{NaMn}_{2-\mathrm{x}} \mathrm{Mg}_{\mathrm{x}} \mathrm{O}_{4}$.

\section{Metodologi Penelitian}

Preparasi Larutan $\mathrm{CH}_{3} \mathrm{COONa},\left(\mathrm{CH}_{3} \mathrm{COO}\right)_{2} \mathrm{Mn}$, $\left(\mathrm{CH}_{3} \mathrm{COO}\right)_{2} \mathrm{Mg}$

Bahan yang digunakan dalam pembuatan elektrolit padat $\mathrm{NaMn}_{2-\mathrm{x}} \mathrm{Mg}_{\mathrm{x}} \mathrm{O}_{4}$ adalah natrium asetat $\left(\mathrm{CH}_{3} \mathrm{COONa}\right)$, mangan asetat $\left(\left(\mathrm{CH}_{3} \mathrm{COO}\right)_{2} \mathrm{Mn}\right)$ dan magnesium asetat $\left(\left(\mathrm{CH}_{3} \mathrm{COO}\right)_{2} \mathrm{Mg}\right)$. Bahan-bahan tersebut masing-masing dilarutkan dalam $20 \mathrm{~mL}$ air dengan konsentrasi $\mathrm{CH}_{3} \mathrm{COONa} 0,1 \mathrm{M},\left(\mathrm{CH}_{3} \mathrm{COO}\right)^{2} \mathrm{Mn} 0,3$ $\mathrm{M}$ dan $\left(\mathrm{CH}_{3} \mathrm{COO}\right)_{2} \mathrm{Mg} \mathrm{0,3} \mathrm{M}$.

Pembuatan Elektrolit Padat $\mathrm{NaMn}_{2-\mathrm{x}} \mathrm{Mg}_{\mathrm{x}} \mathrm{O}_{4}$

Pembuatan elektrolit padat $\mathrm{NaMn}_{2-\mathrm{x}} \mathrm{Mg}_{\mathrm{x}} \mathrm{O}_{4}$ dilakukan dengan melakukan pencampuran masingmasing $20 \mathrm{~mL}$ larutan $\mathrm{CH}_{3} \mathrm{COONa} 0,1 \mathrm{M},\left(\mathrm{CH}_{3} \mathrm{COO}\right)_{2} \mathrm{Mn}$ 0,3 M, dan $\left(\mathrm{CH}_{3} \mathrm{COO}\right)_{2} \mathrm{Mg} \mathrm{0,3} \mathrm{M}$ ke dalam $20 \mathrm{~mL}$ asam sitrat, kemudian dilakukan pengadukan dengan magnetic stirer selama \pm 6 jam. Hasil yang diperoleh berupa larutan bening yang kemudian dilakukan penguapan pada temperatur $80^{\circ} \mathrm{C}$ selama \pm 2 jam menghasilkan campuran berupa gel berwarna merah muda (pink). Selanjutnya dilakukan pengeringan (drying) pada variasi temperatur 150, 160, 170, 180 dan $190^{\circ} \mathrm{C}$ selama 12 jam. Padatan putih kecoklatan yang dihasilkan kemudian di kalsinasi pada $800^{\circ} \mathrm{C}$ selama 6 jam sehingga dihasilkan suatu padatan berwarna coklat tua.

\section{Analisis Hasil}

Hasil yang diperoleh yang berupa padatan berwarna coklat tua dilakukan analisis yang meliputi uji konduktivitas untuk mengetahui kemampuan padatan dalam menghantarkan arus listrik, analisis FTIR untuk mengetahui interaksi molekul dalam padatan, dan sinar-X (X-Ray Diffraction) untuk mengetahui kristalinitas padatan $\mathrm{NaMn}_{2-\mathrm{x}} \mathrm{Mg}_{\mathrm{x}} \mathrm{O}_{4}$.

\section{Hasil Dan Pembahasan}

Pembuatan elektrolit padat $\mathrm{NaMn}_{2-\mathrm{x}} \mathrm{Mg}_{\mathrm{x}} \mathrm{O}_{4}$ dengan variasi temperatur pengeringan $150 ; 160 ; 170 ; 180$; dan $190^{\circ} \mathrm{C}$ menunjukkan hasil seperti pada gambar 1 .
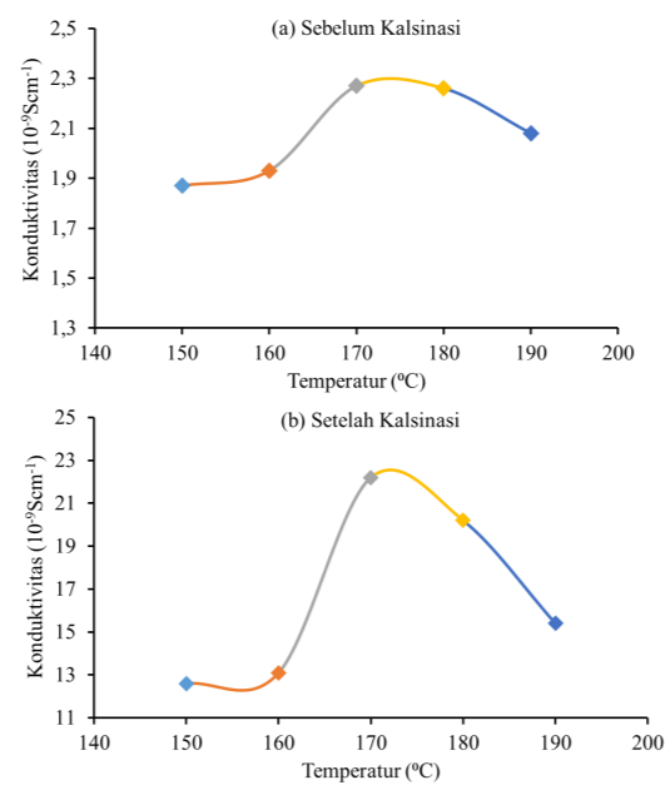

Gambar 1. Hasil pengukuran konduktivitas (a) padatan amorf dan (b) elektrolit padat $\mathrm{NaMn}_{2-\mathrm{x}} \mathrm{Mg}_{\mathrm{x}} \mathrm{O}_{4}$

Berdasarkan 1 dan 2 menunjukkan bahwa pengukuran konduktivitas padatan amorf dan elektrolit padat memiliki nilai konduktivitas tertinggi pada temperatur $170^{\circ} \mathrm{C}$ sedangkan konduktivitas terendah terjadi pada temperatur $150^{\circ}$. Konduktivitas tertinggi terjadi pada temperatur $170^{\circ} \mathrm{C}$ karena pada temperatur $170^{\circ} \mathrm{C}$ memiliki cacat kristal yang lebih banyak dibandingkan dengan temperatur yang lain.

Gambar 2. menunjukkan spektra FTIR dari padatan dengan temperatur $150^{\circ} \mathrm{C}$ dan $170^{\circ} \mathrm{C}$ yang merupakan padatan dengan konduktivitas tertinggi dan terendah.

(a)

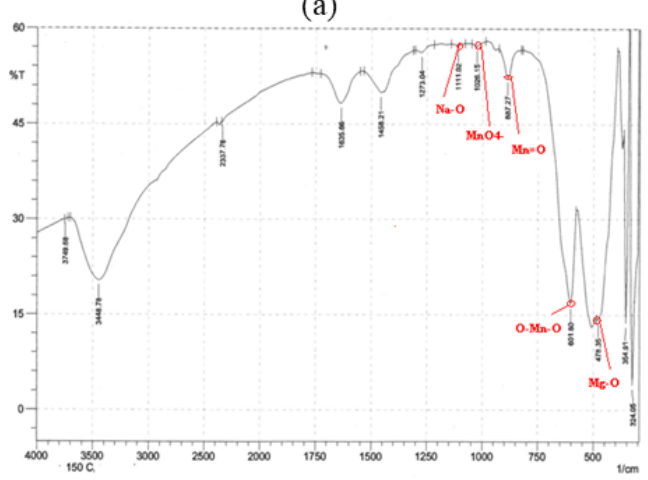

(b)

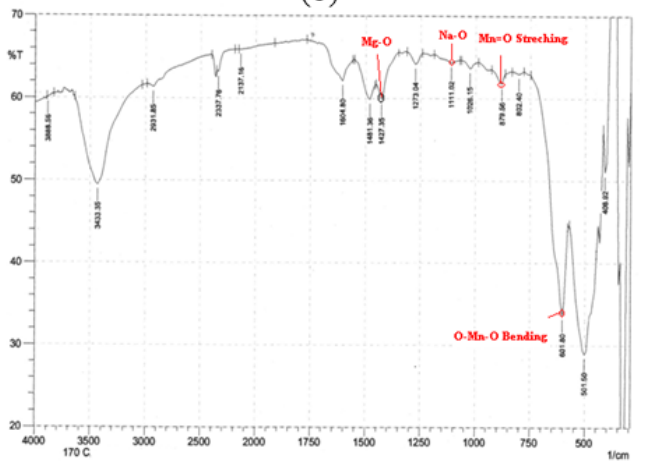

Gambar 2. Hasil Spektra FTIR (a) $150^{\circ} \mathrm{C}$ dan (b) $170^{\circ} \mathrm{C}$ 
Berdasarkan hasil pengukuran Fourier Transform Infrared (FTIR) menunjukkan gugus fungsi yang sama pada setiap sampelnya di mana pada temperatur 150 dan $170^{\circ} \mathrm{C}$ menunjukkan terjadinya vibrasi $\mathrm{Mg}-\mathrm{O}$ stretching, $\mathrm{O}-\mathrm{Mn}$-O bending, $\mathrm{Mn}=\mathrm{O}$ stretching, $\mathrm{MnO}_{4}^{-}$stretching, dan $\mathrm{Na}-\mathrm{O}$.

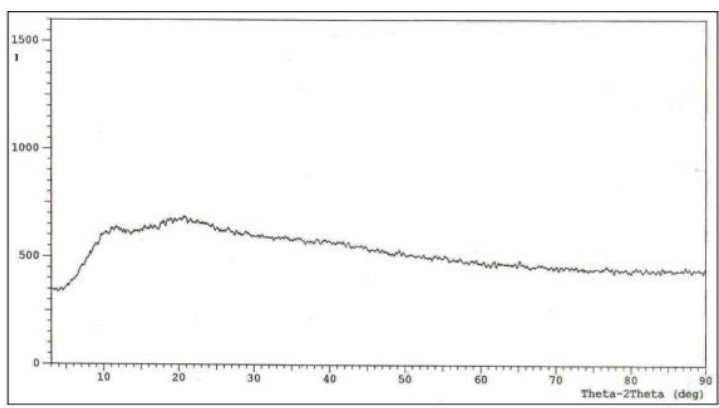

Gambar 3 Hasil XRD sebelum kalsinasi

Gambar 3 menunjukkan hasil analisis XRD sebelum kalsinasi. Hasil analisis menunjukkan padatan amorf yang terbentuk dari proses pengeringan. Konduktivitas padatan amorf terjadi karena adanya migrasi ion melalui bentukan amorf yang beraturan, di mana pada padatan amorf sudah terbentuk pembentukan inti kristal. Pembentukan inti kristal terjadi pada temperatur kristalisasi. Berawal dari pembentukan inti, kristalisasi tumbuh membentuk fasa amorf dan fasa kristalin

Padatan yang telah melalui proses kalsinasi memiliki konduktivitas lebih tinggi, karena selama proses kalsinasi terjadi pembentukan dan penataan struktur awal suatu padatan kristal. Pemanasan tinggi dalam proses kalsinasi yang diikuti dengan pendinginan menyebabkan terbentuknya cacat kristal. Terdapatnya cacat dalam suatu kristal menyebabkan ion-ion dapat bermigrasi sehingga konduktivitas kristal ionik bertambah besar.

Gambar hasil analisis XRD setelah kalsinasi terlihat pada gambar 4 yang menunjukkan terbentuknya kristal $\mathrm{Na}_{2} \mathrm{O}, \mathrm{MgO}, \mathrm{MnO}_{2}$ dan $\mathrm{NaMnO}_{2}$.

(a)

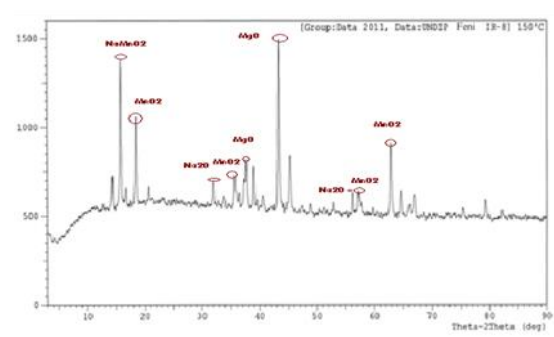

(b)

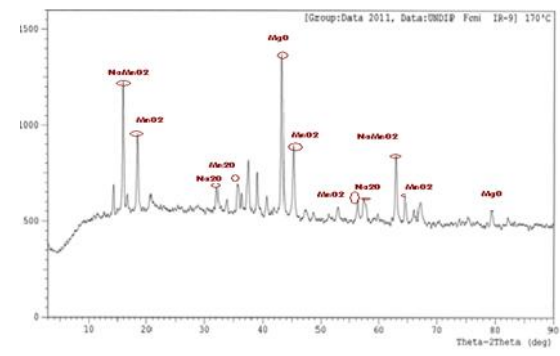

Gambar 4. Hasil XRD (a) $150^{\circ} \mathrm{C}$ dan (b) $170^{\circ} \mathrm{C}$
Berdasarkan gambar 3, hasil XRD pada temperatur 150 dan $170^{\circ} \mathrm{C}$ menunjukkan peak yang sama yaitu $\mathrm{Na}_{2} \mathrm{O}$, $\mathrm{MgO}, \mathrm{MnO}_{2}$ dan $\mathrm{NaMnO}_{2}$. Pergeseran puncak yang dihasilkan oleh XRD disebabkan oleh interaksi atom dalam molekul seperti adanya vibrasi pada struktur molekul NaMn ${ }_{2-x} \mathrm{Mg}_{\mathrm{x}} \mathrm{O}_{4}$.

\section{Kesimpulan}

Hasil pengukuran konduktivitas amorf dan elektrolit padat berdasarkan variasi temperatur pengeringan menunjukkan nilai konduktivitas tertinggi pada temperatur $170^{\circ} \mathrm{C}$ yaitu sebesar $2,27 \times 10^{-9} \mathrm{Scm}^{-1} \mathrm{dan}$ $22,2 \times 10^{-9} \mathrm{Scm}^{-1}$, sedangkan konduktivitas terendah terjadi pada temperatur $150^{\circ} \mathrm{C}$ yaitu sebesar $1,87 \times \mathrm{x}^{-9}$

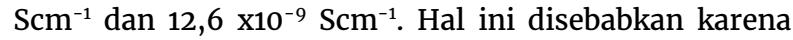
pada temperatur $170^{\circ} \mathrm{C}$ karena memiliki cacat kristal yang lebih banyak dibandingkan temperatur yang lain.

\section{Daftar Pustaka}

[1] K Suryakala, KR Marikkannu, G Paruthimal Kalaignan, $\mathrm{T}$ Vasudevan, Synthesis and electrochemical characterization of $\mathrm{LiMn}_{2} \mathrm{O}_{4}$ and LiNdo. $3 \mathrm{Mn} 1.7 \mathrm{O}_{4}$ as cathode for lithium ion battery, Int. J. Electrochem. Sci, 3, (2008) 136-144

[2] Tsutomu Minami, Masahiro Tatsumisago, Masataka Wakihara, Chiaki Iwakura, Shinzo Kohjiya, Isao Tanaka, Solid state ionics for batteries, Springer Science \& Business Media, 2006.

[3] Sung-Tae Lee, Seung-Gyun Kim, Min-Ho Jang, Sul-Hyee Hwang, Jung-Rim Haw, Sung-Ki Lim, The phase relationship of Na-beta-aluminas synthesized by a sol-gel process in the ternary system Na2O-Al2O3-Li2O, Journal of Ceramic Processing Research, 11, 1, (2010) 86-91

[4] Amrtha Bhide, K Hariharan, Sodium ion transport in $\mathrm{NaPO}_{3}-\mathrm{Na}_{2} \mathrm{SO}_{4}$ glasses, Materials Chemistry and Physics, 105, 2, (2007) 213-221 http://dx.doi.org/10.1016/j.matchemphys.2007.04.0 44 